\title{
Effects of malathion and carbendazim on Amazonian freshwater organisms: comparison of tropical and temperate species sensitivity distributions
}

\author{
Andreu Rico - Andrea V. Waichman • \\ Rachel Geber-Corrêa • Paul J. van den Brink
}

Accepted: 16 January 2011/Published online: 26 January 2011

(C) The Author(s) 2011. This article is published with open access at Springerlink.com

\begin{abstract}
The risk assessment of pesticides for freshwater ecosystems in the Amazon has relied on the use of toxicity data and water quality criteria derived for temperate regions due to a lack of ecotoxicological studies performed with indigenous species. This leaves an unknown margin of uncertainty for the protection of Amazonian ecosystems, as differences in environmental conditions and species sensitivity are not taken into account. To address this issue, the acute toxic effects of malathion (an organophosphorus insecticide) and carbendazim (a benzimidazole fungicide) were assessed on five fish and five freshwater invertebrates endemic to the Amazonian region. Subsequently, the intrinsic sensitivity of Amazonian and temperate freshwater species was compared using the species sensitivity distribution (SSD) concept. Amazonian species sensitivity to malathion was found to be similar to that of their temperate counterparts, with LC50 values ranging between 111 and $1507 \mu \mathrm{g} / \mathrm{l}$ for fish species and 2.1-426 $\mu \mathrm{g} / \mathrm{l}$ for arthropod species. However, Amazonian fish appeared to be slightly less sensitive for carbendazim than temperate
\end{abstract}

\footnotetext{
A. Rico $(\square)$. P. J. van den Brink

Department of Aquatic Ecology and Water Quality

Management, Wageningen University, Wageningen University and Research Centre, P.O. Box 47, 6700 AA Wageningen, The Netherlands

e-mail: andreu.rico@wur.nl

A. V. Waichman · R. Geber-Corrêa

Instituto de Ciências Biológicas, Universidade Federal do Amazonas, Av. Rodrigo Otávio Jordão Ramos 3000, Manaus, AM 69077-000, Brazil

P. J. van den Brink

Alterra, Centre for Water and Climate, Wageningen University and Research Centre, P.O. Box 47, 6700 AA Wageningen,

The Netherlands
}

fish with LC50 values ranging between 1648 and $4238 \mu \mathrm{g} /$ 1, and Amazonian invertebrates were found to be significantly more resistant than their temperate counterparts, with LC50 values higher than $16000 \mu \mathrm{g} / \mathrm{l}$. The results of this study suggest that for these compounds, the use of water quality criteria derived with laboratory toxicity data for temperate species will result in a sufficient protection level for Amazonian freshwater organisms. Recommendations for further research include the validation of threshold concentrations derived with temperate standard test species and with the SSD model with semi-field experiments considering larger assemblages of indigenous species under local environmental conditions.

Keywords Amazon - Ecological risk assessment · Freshwater ecosystems · Pesticides - Species sensitivity distributions

\section{Introduction}

The Amazon is one of the most important tropical areas on the planet, comprising approximately $40 \%$ of the world's remaining tropical rainforest and harbouring an enormous diversity of flora and fauna species (Laurance et al. 2001). The Amazon basin is made up of innumerable rivers, lakes, channels, floodplain areas and freshwater swamp forests, constituting a hotspot of diversity of freshwater insects and crustaceans (Fittkau 1982), and containing approximately $19 \%$ of the world's freshwater fish fauna, with an estimated number of 2,072 endemic species, higher than the total number of fish species of the Paleartic $(1,844)$ and Neartic (1,411) regions (Lévêque et al. 2008).

During the last decades, the use of pesticides in the agricultural areas of the Central Amazon has increased 
exponentially, constituting one of the main sources of nonpoint pollution for adjacent aquatic ecosystems. The application of pesticides has been regarded by Amazonian farmers as one of the main Green Revolution strategies to increase their agricultural productivity and improve their economic status (Ecobichon 2001; Waichman et al. 2002, 2007). The increased demand for fruit and vegetables in the main urban areas of the Amazon, and the introduction of non-traditional crops which are more susceptible to insects, fungi and other plagues, and have to compete with the native vegetation, have forced Amazonian farmers to use pesticides intensively (Waichman et al. 2007; Römbke et al. 2008). Furthermore, the study by Waichman et al. (2007) pointed out that the lack of technical support and an inadequate understanding of the potential risks that pesticides may pose to human health and the environment are the main causes of the indiscriminate application of pesticides, which is frequently accompanied by incorrect practices such as washing of application equipments in the nearby water bodies or container disposal in the banks of the rivers. In addition, particular environmental conditions of the Amazonian region such as heavy rains and annual floods are likely to favour pesticide dispersion into water bodies, posing a potential threat for the enormous diversity of target and non-target organisms inhabiting aquatic ecosystems in the vicinity of agricultural fields. Consequently, there is an increasing need to evaluate the risks that the current use of pesticides may pose to the biodiversity and sustainability of Amazonian freshwater ecosystems.

Ecotoxicological research into the fate and effects of agrochemicals on aquatic ecosystems surrounding agricultural fields has mainly focused on temperate countries (i.e., EU, USA), while little information is available for tropical ecosystems (Castillo et al. 1997; Lacher and Goldstein 1997; Daam and Van den Brink 2010). The lack of toxicity studies for tropical species has forced scientists from tropical countries to perform ecological risk assessment studies based on toxicity data and water quality criteria (WQC) derived for the risk assessment of pesticides in temperate regions. Several authors have hypothesized that the extrapolation of temperate toxicity data for tropical hazard assessments may place tropical ecosystems at undue risks, since differences between temperate and tropical ecosystems in terms of environmental conditions and species sensitivity are not normally taken into account (Castillo et al. 1997; Lacher and Goldstein 1997; Kwok et al. 2007; Römbke et al. 2008). It has been demonstrated that different thermal conditions and water quality parameters can influence the toxicity of pesticides to freshwater organisms. For instance, Palawski and Knowles (1986) showed that the toxicity of the fungicides carbendazim and benomyl to two species of fish (Ictalurus punctatus and Oncorhynchus mykiss) was significantly influenced by changes in temperature,
$\mathrm{pH}$ and water hardness. A similar study was conducted by Howe et al. (1994), who evaluated the effects of temperature and $\mathrm{pH}$ on the toxicity of four compounds (terbufos, trichlorfon, 4-nitrophenol and 2,4-dinitrophenol) to the amphiphod Gammarus pseudolimnaeus and the rainbow trout O. mykiss. In the majority of these experiments, the increase of temperature resulted in a higher sensitivity of these species, whereas water hardness was found to be negatively correlated to the toxicity of these compounds. A consistent relationship between $\mathrm{pH}$ and toxicity could not be demonstrated. The effect of water parameters such as temperature, $\mathrm{pH}$ and water hardness on the toxicity of pesticides is thought to vary considerably depending on the compound and the studied species and, hence, a clear pattern used to extrapolate effects of pesticides over different climatic regions cannot be identified. In addition, the assessment of the toxicity of pesticides for tropical ecosystems based on the assessment of a temperate single-species exposed to a range of water parameters different to their natural conditions will add an additional stress to the studied species and the results will be seriously biased. Thus, the comparison of species sensitivities to pesticide exposure under different climatic regions can only be assessed by comparing responses of organisms under environmental conditions that resemble their natural ecosystems and denote optimum health for the studied species (Dyer et al. 1997). Several researchers have investigated whether toxicity datasets and pesticide threshold concentrations for aquatic ecosystems derived in the temperate region can be used for the risk assessment of pesticides in the tropics by comparing results of laboratory and semi-field experiments conducted in different latitudes (Table 1). These studies showed that, for most of the studied taxonomic groups and compounds, temperate toxicity data may be sufficiently protective for tropical species. However, these studies were mainly based on toxicity data from Asian indigenous species, while the sensitivities of the tropical species of America and Africa have been underrepresented. It should be highlighted that the relative abundance and variability of species within each taxonomic group can vary between tropical regions (Daam and Van den Brink 2010), and hence, inter-species sensitivity comparisons and regional risk assessment studies should consider local species in order to get a more realistic picture of the sensitivity of the ecosystem that is intended to be protected.

Knowledge about the effects of pesticides on Amazonian freshwater species is still very limited and differences between the sensitivity of Amazonian and temperate freshwater species have only been evaluated for one compound (i.e., parathion-methyl) by Rico et al. 2010, showing that Amazonian freshwater organisms have a similar sensitivity to parathion-methyl than their temperate counterparts. In the present study, the approach developed in Rico et al. 2010 
Table 1 Comparison of temperate and tropical species sensitivity to pesticides performed by several authors

\begin{tabular}{|c|c|c|c|c|c|}
\hline Pesticide & Type & Most sensitive region & Species group & Toxicity data & Reference \\
\hline Carbaryl & I & Similar & \multirow{4}{*}{ Fish } & \multirow{4}{*}{ A-SS-LB } & \multirow{4}{*}{ Dyer et al. (1997) } \\
\hline DDT & I & Temperate $^{\mathrm{a}}$ & & & \\
\hline Lindane & I & Similar & & & \\
\hline Malathion & I & Similar & & & \\
\hline Chlorpyrifos & I & Similar & \multirow{3}{*}{ Arth } & \multirow{3}{*}{ A-SS-LB } & \multirow{3}{*}{ Maltby et al. (2005) } \\
\hline Fenitrothion & I & Similar & & & \\
\hline Carbofuran & I & Similar & & & \\
\hline Carbaryl & I & Temperate & \multirow{6}{*}{ Vert + Inv } & \multirow{6}{*}{ A-SS-LB } & \multirow{6}{*}{ Kwok et al. (2007) } \\
\hline DDT & I & Temperate & & & \\
\hline Malathion & I & Temperate & & & \\
\hline Chlorpyrifos & I & Tropical & & & \\
\hline Lindane & I & Similar & & & \\
\hline Chlordane & I & Similar & & & \\
\hline Chlorpyrifos & I & Similar & Inv & LT-CL-SFE & Daam et al. (2008) \\
\hline Carbendazim & $\mathrm{F}$ & Similar & Inv & LT-CL-SFE & Daam et al. (2009a) \\
\hline Linuron & $\mathrm{H}$ & Similar & Inv + Phyto & LT-CL-SFE & Daam et al. (2009b) \\
\hline Parathion-methyl & I & Similar & Fish, Arth & A-SS-LB & Rico et al. (2010) \\
\hline
\end{tabular}

${ }^{a}$ Significant differences

$I$ insecticide, $F$ fungicide, $H$ herbicide

$A$-SS-LB Acute single-species laboratory bioassays

$L T$-C-SFE Long-term community-level semi-field experiments

was further extended by assessing the effects of two different pesticides (malathion and carbendazim) on Amazonian indigenous fish and invertebrates and comparing their inherent pesticide sensitivity with toxicity datasets developed for temperate species. Furthermore, implications for the use of temperate toxicity data for the ecological risk assessment of pesticides in the Amazon are derived.

\section{Materials and methods}

Test compounds

The organophosphorus insecticide malathion [diethyl (dimethoxyphosphinothioylthio)succinate] and the benzimidazole fungicide carbendazim [methyl benzimidazol-2ylcarbamate] were selected as model compounds to assess the effects of pesticides on the Amazonian organisms based on their potential hazard to aquatic organisms, their relative use among Amazonian farmers and on the availability and quality of data on toxicity for temperate species. Toxicity tests were performed with emulsifiable concentrate formulations of Malathion $500^{\circledR}$ (active ingredient malathion $500 \mathrm{~g} / \mathrm{l}$ ) and Derosal $500^{\circledR}$ (active ingredient carbendazim $500 \mathrm{~g} / \mathrm{l})$ purchased in Manaus (Amazon State, Brazil).
Test organisms

The effects of malathion and carbendazim were assessed on five fish species (Colossoma macropomum, Hyphessobrycon erythrostigma, Paracheirodon axelrodi, Nannostomus unifasciatus and Otocinclus affinis) and five invertebrate species, the later consisting of one crustacean (Macrobrachium ferreirai), three insect (Hydrophilus sp., Buenoa unguis, Palustra laboulbeni) and one freshwater snail (Pomacea dilioides) species, endemic to the Amazon (Tables 2, 3). Fish specimens were purchased from ornamental fish retailers and acclimatised to the laboratory conditions for at least 7 days before the start of the experiments. Invertebrates were collected 1 or 2 days before the start of the experiments, from uncontaminated shallow lakes, ponds or streams in the vicinity of Manaus, Brazil. Species selection aimed to represent at least two of the most representative/sensitive groups of invertebrates recommended by the European Union for risk assessment of chemicals in the environment (EU 2003): i.e., including insects and crustaceans, and a species in a phylum other than Arthropoda (in this case Mollusca: $P$. dilioides). The taxonomic classification of the studied species, length and weight of the individuals tested are presented in Rico et al. (2010). 
Table 2 Life-history stage of the studied species, results of acute toxicity tests with the insecticide malathion and measured water parameters

\begin{tabular}{|c|c|c|c|c|c|}
\hline Species & $\begin{array}{l}\text { Life-history } \\
\text { stage }\end{array}$ & $\begin{array}{l}\text { LC50-96 h }(\mu \mathrm{g} / 1)(95 \% \\
\text { confidence limits) }\end{array}$ & $\begin{array}{l}\text { Temp. }\left({ }^{\circ} \mathrm{C}\right) \\
\text { mean } \pm \mathrm{SD}\end{array}$ & $\mathrm{pH}, \min -\max$ & $\begin{array}{l}\mathrm{O}_{2}(\mathrm{mg} / \mathrm{l}) \\
\min -\max \end{array}$ \\
\hline \multicolumn{6}{|l|}{ Fish } \\
\hline Colossoma macropoтит & Alevin & $1507(1359-1671)$ & $27.1 \pm 0.2$ & $6.7-8.0$ & $5.5-6.5$ \\
\hline Hyphessobrycon erythrostigma & (Sub) Adult & $252(191-333)$ & $26.7 \pm 0.4$ & $5.6-7.8$ & $5.3-6.4$ \\
\hline Paracheirodon axelrodi & (Sub) Adult & $247^{\mathrm{a}}$ & $26.4 \pm 0.2$ & $6.5-7.9$ & $5.4-6.4$ \\
\hline Nannostomus unifasciatus & (Sub) Adult & $111(82.2-149)$ & $26.7 \pm 0.4$ & $5.6-7.8$ & $5.3-6.4$ \\
\hline Otocinclus affinis & (Sub) Adult & $1067(837-1360)$ & $27.2 \pm 0.3$ & $6.8-8.5$ & $4.3-6.4$ \\
\hline \multicolumn{6}{|l|}{ Invertebrates } \\
\hline Macrobrachium ferreirai & Adult & $398(312-508)^{\mathrm{b}}$ & $27.1 \pm 0.3$ & $6.6-7.5$ & $5.0-6.2$ \\
\hline Hydrophilus sp. & (Sub) Adult & $34.5(25.3-46.9)$ & $27.3 \pm 0.7$ & $6.8-7.6$ & - \\
\hline Buenoa unguis & Adult & $2.10(1.70-2.70)^{\mathrm{c}}$ & $25.9 \pm 0.7$ & $5.9-7.0$ & - \\
\hline Palustra laboulbeni & Larvae & $426(359-505)$ & $25.9 \pm 0.1$ & $6.2-7.7$ & - \\
\hline Pomacea dilioides & (Sub) Adult & 22075 (19704-24733) & $26.5 \pm 0.3$ & $6.7-8.0$ & - \\
\hline
\end{tabular}

a Confidence limits not available due to singularity in the regression model

${ }^{b}$ Estimated because of cannibalism in controls (cannibalism was not regarded as a negative response)

${ }^{\mathrm{c}}$ LC50 calculated at $72 \mathrm{~h}$ of exposure due to high mortality in controls

Table 3 Life-history stage of the studied species, results of acute toxicity tests with the fungicide carbendazim and measured water parameters

\begin{tabular}{|c|c|c|c|c|c|}
\hline Species & Life-history stage & $\begin{array}{l}\text { LC50-96 h }(\mu \mathrm{g} / \mathrm{l}) \\
(95 \% \text { confidence limits })\end{array}$ & $\begin{array}{l}\text { Temp. }\left({ }^{\circ} \mathrm{C}\right) \\
\text { mean } \pm \mathrm{SD}\end{array}$ & $\mathrm{pH}, \min -\max$ & $\begin{array}{l}\mathrm{O}_{2}(\mathrm{mg} / \mathrm{l}) \\
\min -\max \end{array}$ \\
\hline \multicolumn{6}{|l|}{ Fish } \\
\hline Colossoma mасrоротит & Alevin & $4162(3435-5043)^{\mathrm{d}}$ & $26.2 \pm 0.4$ & $6.6-7.8$ & $5.0-6.2$ \\
\hline Hyphessobrycon erythrostigma & (Sub) Adult & $3690(2911-4678)$ & $26.8 \pm 0.3$ & $6.3-7.9$ & $4.5-6.7$ \\
\hline Paracheirodon axelrodi & (Sub) Adult & $1648(1366-1987)$ & $26.9 \pm 0.1$ & $6.3-7.3$ & $5.4-6.7$ \\
\hline Nannostomus unifasciatus & (Sub) Adult & $4138(3332-5139)$ & $26.8 \pm 0.3$ & $6.3-7.9$ & $4.5-6.7$ \\
\hline Otocinclus affinis & (Sub) Adult & $4238(3605-4981)$ & $27.1 \pm 0.6$ & $7.0-8.1$ & $5.3-6.3$ \\
\hline \multicolumn{6}{|l|}{ Invertebrates } \\
\hline Macrobrachium ferreirai & Adult & $16767(11684-24060)^{\mathrm{b}}$ & $27.3 \pm 0.2$ & $6.6-7.6$ & $4.4-6.2$ \\
\hline Hydrophilus sp. & (Sub) Adult & 80669 (62534-104063) & $26.9 \pm 0.3$ & $6.6-7.7$ & - \\
\hline Buenoa unguis & Adult & $73822^{\mathrm{a}, \mathrm{c}}$ & $26.8 \pm 0.3$ & $6.2-7.4$ & - \\
\hline Palustra laboulbeni & Larvae & $111329(100395-123453)$ & $26.6 \pm 0.4$ & $6.1-7.8$ & - \\
\hline Pomacea dilioides & (Sub) Adult & $1758576(1679134-1841776)$ & $27.3 \pm 0.6$ & $6.8-7.7$ & - \\
\hline
\end{tabular}

${ }^{a}$ Confidence limits not available due to singularity in the regression model

b Estimated because of cannibalism in controls (cannibalism was not regarded as a negative response)

${ }^{c}$ LC50 calculated at $72 \mathrm{~h}$ of exposure due to high mortality in controls

${ }^{\mathrm{d}}$ Confidence limits corrected for heterogeneity

Acute toxicity tests

Single-species toxicity tests were performed in glass vessels with a volume of 2.51 for fish and 11 for macroinvertebrates, with the exception of M. ferreirai, for which 21 of test media was used. Test media were prepared by diluting stock solutions of the test compounds in tap water from the experimental facilities of Embrapa Amazônia Ocidental, Brazil. The tap water used for the experiments had characteristics similar to those of the Amazonian black-waters (Furch 1984), with a low nutrient content $\left(0.005 \mathrm{mg} / \mathrm{l} \mathrm{NH}{ }_{4}^{+}\right.$and $\left.0.05 \mathrm{mg} / \mathrm{PO}_{4}-\mathrm{P}\right)$, low alkalinity $\left(2.2-2.3 \mathrm{mg} / \mathrm{l}\right.$ of $\left.\mathrm{CaCO}_{3}\right)$ and slightly acid $\mathrm{pH}(5.8-6.8)$. The water used for the experiments with $P$. dilioides, however, was taken from the uncontaminated pond where they were collected, since gastropods cannot live in extremely soft waters. The water used for the $P$. dilioides experiments was first filtered through a pre-washed glass 
fibre filter (Whatman $\mathrm{GF} / \mathrm{C}$, pore size $1.2 \mu \mathrm{m}$ ) and had a higher alkalinity level $\left(63.1 \mathrm{mg} \mathrm{CaCO}_{3} / \mathrm{l}\right)$, higher nutrient concentrations $\left(0.005 \mathrm{mg} / 1 \mathrm{NH}_{4}{ }^{+}\right.$and $\left.0.05 \mathrm{mg} / 1 \mathrm{PO}_{4}-\mathrm{P}\right)$, and higher $\mathrm{pH}(6.8-7.8)$ than the tap water used for the rest of experiments.

Fish and invertebrate mortality was used as an endpoint for assessing the effects of malathion and carbendazim. Five treatment levels and an untreated control were used to calculate the dose-response curve and the lethal concentration for $50 \%$ of the individuals after an exposure period of $96 \mathrm{~h}$ (LC50-96 h). All tests were done in triplicate $(n=3)$ with ten individuals per test unit. Laboratory tests were set up as static with a single application of pesticide and were carried out by adapting the guidelines of the Organisation for Economic Co-operation and Development (OECD) for testing the acute effects of chemicals on aquatic organisms (OECD 1992) to the Amazonian water quality parameters and environmental conditions (temperature of $26 \pm 2{ }^{\circ} \mathrm{C}$, slightly acid $\mathrm{pH}$ and photoperiod of $12 \mathrm{~h}$ of natural light). In order to ensure sufficient oxygen concentration in the test media (higher than $60 \%$ of the air saturation value at the test temperature), an aeration system was installed for the experiments performed with fish and the freshwater shrimp M. ferreirai. Since the rest of the invertebrate species studied are air-breathers or are capable of combining both respiration types, tests with these species were performed without water aeration. In accordance with the OECD guidelines, intervals between successive nominal concentrations did not exceed a factor of 2.2, and tests were only accepted when mortality in the control vessels did not exceed $10 \%$ for fish or $20 \%$ for invertebrates. Water quality parameters of the test media (i.e., temperature, $\mathrm{pH}$, dissolved oxygen) and mortality of test individuals were measured on a daily basis as described in Rico et al. (2010).

The ToxRat Professional Version 2.07 program (ToxRat 2003) was used to calculate the LC50-96 $\mathrm{h}$ values. The LC50 for each species and its 95\% confidence intervals were calculated by a log concentration-probit regression model. Confidence intervals were calculated when at least one partial response was observed between 0 and $100 \%$ effect (singularity in regression model). The Abbott's formula was used by the program to correct for mortality in the untreated controls.

Comparison of pesticide sensitivity between

Amazonian and temperate freshwater species

The inherent sensitivity of temperate freshwater species to the selected compounds was assessed using the same toxicity data as those used in the study by Maltby et al. (2005, 2009). Temperate region toxicity data had been collected from existing toxicity databases (e.g. www.epa.gov/ecotox and De Zwart 2002) and had been selected from singlespecies toxicity studies (EC50 and LC50) with exposure durations of between 2 and 21 days for fish and between 1 and 7 days for invertebrates. When selecting a toxicity value for a specific species or for a genus with no specific species name, the geometric mean for all the reported toxicity values was calculated. The water quality parameters corresponding to the temperate toxicity data used in the present study were: temperature $21.2 \pm 4.8^{\circ} \mathrm{C}(n=83)$, pH $7.5 \pm 0.4(n=48)$, water hardness $108.3 \pm 95.0 \mathrm{mg} / \mathrm{l}$ $\mathrm{CaCO}_{3} \quad(n=38)$ and dissolved oxygen $7.5 \pm 1.3 \mathrm{mg} / \mathrm{l}$ $(n=30)$.

The sensitivity of Amazonian and temperate freshwater organisms was compared using the species sensitivity distribution concept (SSD) as described in Rico et al. (2010). Species sensitivity distribution curves were calculated with the ETX 2.0 software (Van Vlaardingen et al. 2004). Lognormality was tested using the Anderson-Darling goodnessof-fit test, with normality of toxicity data assumed at $p \geq 0.05$ (Posthuma et al. 2002). Significance of differences between temperate and tropical SSDs was evaluated by the two-sample Kolmogorov-Smirnov test, calculated using the SYSTAT 12 statistical package (SYSTAT 2007). The hazardous concentrations for the 5 and $50 \%$ of species (HC5 and HC50 respectively) were calculated according to Aldenberg and Jaworska (2000). Since large differences in insecticide sensitivity were expected between arthropods and nonarthropods (Maltby et al. 2005), the comparison between Amazonian and temperate freshwater invertebrates as regards their sensitivity to malathion was made exclusively based on data for arthropods.

\section{Results}

Acute toxicity tests

The results of short-term toxicity tests of malathion and carbendazim for Amazonian freshwater organisms are shown in Tables 2 and 3, respectively, together with the results of the water quality parameters measured during the experiments. Non-mortal cannibalism in tests with M. ferreirai (i.e. damage by pincers) was consistently observed in all treatment levels. This was, however, not evaluated as a negative effect, and mortality at controls did not exceed $20 \%$. The lethal concentration for B. unguis was calculated using $72 \mathrm{~h}$ data, as mortality in the control treatment exceeded the $20 \%$ threshold after the third day of the experiment.

The tested fish species were found to be relatively sensitive to malathion, with LC50-96 $\mathrm{h}$ values ranging from 111 to $1,507 \mu \mathrm{g} / \mathrm{l}$, with $N$. unifasciatus being the most sensitive species (Table 2). LC50 values for invertebrates 
exposed to malathion ranged from 2.1 to $22,075 \mu \mathrm{g} / \mathrm{l}$. B. unguis (Hemiptera) and Hydrophilus sp. (Coleoptera) were found to be the species most sensitive to malathion, with LC50 values of 2.1 and $34.5 \mu \mathrm{g} / \mathrm{l}$, respectively. Pomacea dilioides (Gastropoda) was found to be the species least sensitive to malathion with a LC50 more than 50 times higher than the rest of the tested species.

Carbendazim was found to be moderately toxic to Amazonian fish, with LC50 values ranging from 1,648 to $4,238 \mu \mathrm{g} / \mathrm{l}$, with $P$. axelrodi being the most sensitive species followed by $H$. erythrostigma (Table 3 ). The invertebrate species we studied can be characterized as non-sensitive to acute exposure to carbendazim, as their LC50 values were found to be markedly higher than the solubility of this compound in water, which ranges from 8 to $28 \mathrm{mg} / \mathrm{l}$ depending on the $\mathrm{pH}$ (WHO 1993). Consequently, the LC50 results found in the present study should be considered a mere estimation, since precipitation of carbendazim was observed in the glass vessels.

\section{Comparison of SSDs}

The SSD curves constructed for malathion and carbendazim with Amazonian and temperate freshwater organisms are shown in Fig. 1. The results of the two-sample Kolmogorov-Smirnov test did not reveal significant differences between sensitivity distributions of temperate and Amazonian fish exposed to malathion $\left(k s=0.53, n_{1}=36, n_{2}=5\right.$, $p=0.15)$ and carbendazim $\left(k s=0.75, n_{1}=4, n_{2}=5\right.$, $p=0.13$ ), nor between temperate and Amazonian arthropods exposed to malathion $\left(k s=0.37, n_{1}=76, n_{2}=4\right.$, $p=0.68)$. However, exposure to the fungicide carbendazim led to significant differences in sensitivities between the temperate and Amazonian SSDs of invertebrates, when both including arthropods and non-arthropods species $(k s=$ $\left.1.00, n_{1}=7, n_{2}=5, p<0.001\right)$. Temperate invertebrate species were found to be significantly more sensitive to carbendazim than their Amazonian counterparts. The results of the Anderson-Darling goodness-of-fit test $(\alpha=0.05)$ indicated that most of the toxicity datasets we studied satisfied the conditions of being normally distributed, with the exception of the dataset for sensitivity of temperate fish species to malathion, the dataset for sensitivity of Amazonian fish species to carbendazim and the dataset for sensitivity of temperate arthropods to malathion.

The median HC5 and HC50 values for temperate and Amazonian SSDs with their lower (95\%) and upper (5\%) confidence limits are shown in Table 4. For the insecticide malathion, median HC5 and HC50 values for Amazonian fish and freshwater invertebrates were found to be similar to those calculated for their temperate counterparts. However, different results were observed for the fungicide carbendazim, as median HC5 and HC50 values for temperate fish were found to be considerably lower than those calculated for Amazonian species. Temperate invertebrates were found to be more sensitive to carbendazim than the Amazonian species we tested, with HC5 and HC50 values more than three orders of magnitude lower (Fig. 1; Table 4).
Fig. 1 Species sensitivity distributions for temperate (circles) and Amazonian (squares) freshwater species exposed to a malathion: fish, b malathion: arthropods, c carbendazim: fish, d carbendazim: invertebrates (a) Malathion: fish

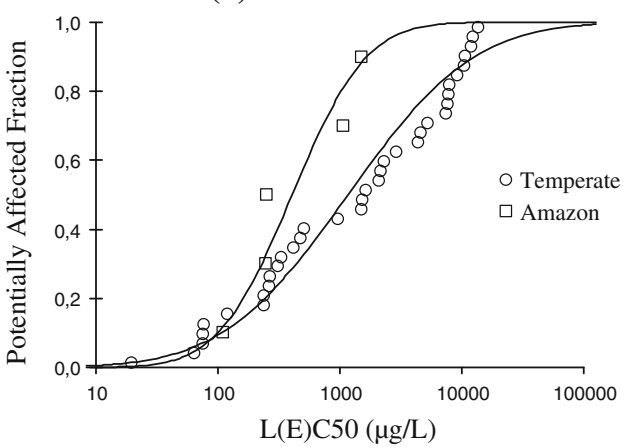

(c) Carbendazim: fish

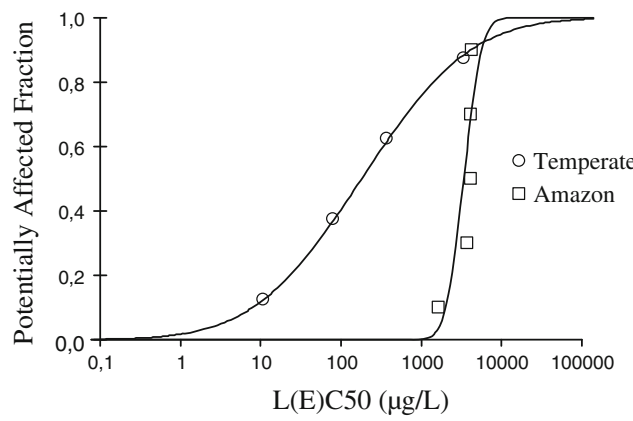

(b) Malathion: arthropods

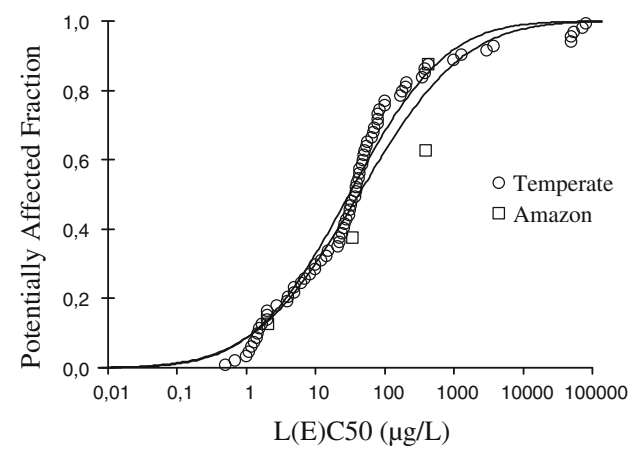

(d) Carbendazim: invertebrates

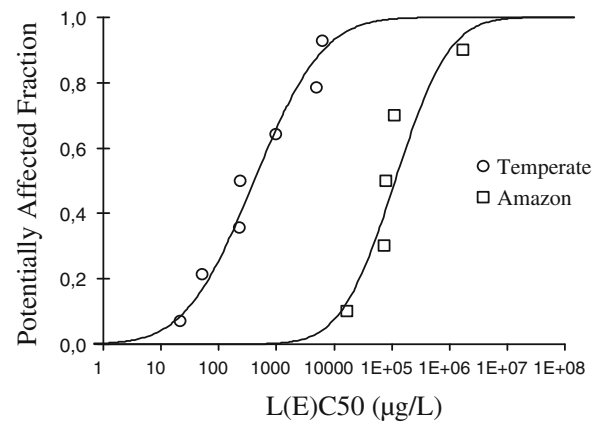


Table 4 Median hazardous concentrations for $5 \%$ and $50 \%$ of species $\left(\mathrm{HC}_{5}\right.$ and $\mathrm{HC}_{50}$ respectively; $\left.\mu \mathrm{g} / \mathrm{l}\right)$ and their lower $(95 \%)$ and upper (5\%) confidence limits, derived from the SSDs shown in Fig. 1 for malathion (a) and carbendazim (b), in $\mu \mathrm{g} / \mathrm{l}$

\begin{tabular}{llcc}
\hline \multicolumn{2}{c}{ Temperate } & Amazon \\
\hline $\begin{array}{llc}\text { (a) Malathion } \\
\text { Fish }\end{array}$ & & & \\
& $\mathrm{HC}_{5}$ & $53.0(20.9-107)$ & $57.6(4.00-166)$ \\
Arthropods & $\mathrm{HC}_{50}$ & $1166(690-1970)$ & $406(143-1157)$ \\
& $\mathrm{HC}_{5}$ & $0.45(0.19-0.94)$ & $0.31(0.00008-4.75)$ \\
(b) Carbendazim & $\mathrm{HC}_{50}$ & $42.0(25.0-71.0)$ & $30.54(1.60-580)$ \\
Fish & $\mathrm{HC}_{5}$ & $2.10(0.0007-29.5)$ & $1643(614-2428)$ \\
& $\mathrm{HC}_{50}$ & $181(10.3-3184)$ & $3384(2298-4984)$ \\
Invertebrates & $\mathrm{HC}_{5}$ & $9.80(0.30-56.6)$ & $5620(92.8-28630)$ \\
& $\mathrm{HC}_{50}$ & $411(84.4-2003)$ & $114300(22760-574600)$ \\
\hline
\end{tabular}

\section{Discussion}

Effects of malathion and carbendazim on Amazonian freshwater organisms

The results of the short-term toxicity tests show that the acute toxicity of the model compounds used in this study differs widely among Amazonian species. The tested insects and crustaceans were found to be highly sensitive to the insecticide malathion, and these findings are in line with several studies showing a high toxicity of malathion to arthropod invertebrates (Key et al. 1998; Saler and Saglam 2005; Van Wijngaarden et al. 2005). Pomacea dilioides, however, was found to be highly resistant to malathion. This is in agreement with the results of the experiment conducted by Rico et al. (2010) using parathion-methyl and with other studies showing a high tolerance of apple snails to insecticides (Schroer et al. 2004; Daam et al. 2009a). Malathion was found to be very toxic to the tested Amazonian fish, with LC50 values comparable to the concentrations reported by Dyer et al. (1997) for other tropical fish species.

A different pattern, however, was observed for the toxicity data estimated for the fungicide carbendazim. All the Amazonian invertebrate species tested were found to be highly resistant to this compound, with LC50 values between 10 and 100 times higher than those calculated for Amazonian fish (Table 3). Several studies have pointed out the high tolerance of some freshwater invertebrates to carbendazim in acute toxicity tests in the laboratory (Van Wijngaarden et al. 1998; Satapornvanit et al. 2009) as well as in model ecosystem studies performed under temperate (Cuppen et al. 2000) and tropical conditions (Daam et al. 2009a). High tolerance of Hydrophilidae and Notonectidae species of the tropical regions of Thailand to carbendazim has been already reported in the study by Daam et al. (2009a), and can explain the low sensitivity of Hydrophilus sp. (Hydrophilidae) and B. unguis (Notonectidae) found in the present study. The LC50 values for Amazonian fish species estimated in the present study were found to be at least two-fold higher than the acute toxicity values for fingerlings $(1.2 \mathrm{~g}$ ) of $O$. mykiss (LC50-96 h = $870 \mu \mathrm{g} / \mathrm{l}$ ) and $I$. punctatus (LC50-96 $\mathrm{h}=19 \mu \mathrm{g} / \mathrm{l}$ ) estimated at 10 and $22^{\circ} \mathrm{C}$ respectively, and with a water hardness of 40-48 mg/l $\mathrm{CaCO}_{3}$ (Palawski and Knowles 1986).

Comparison of malathion and carbendazim sensitivity between Amazonian and temperate species

Inter-species differences in sensitivity between temperate and Amazonian organisms were not demonstrated for the insecticide malathion. These results are in line with the study by Rico et al. (2010), who did not find sensitivity differences between temperate and Amazonian species (i.e., fish and invertebrates) for the organophosphate insecticide parathion-methyl and with several studies that compared laboratory toxicity data of tropical and temperate freshwater species to malathion and other synthetic insecticides (Dyer et al. 1997; Maltby et al. 2005; Kwok et al. 2007; Table 1). The results of the SSD comparison indicated that most of the temperate fish species are slightly to much more sensitive to carbendazim than their Amazonian counterparts. The variation in LC50 between temperate species is much larger than that between the Amazonian species, with an overlap in the upper tails of the curves (Fig. 1c). Therefore, significant differences could not be demonstrated. Differently to what was observed for the other inter-species comparisons, Amazonian invertebrates were found to be significantly less sensitive to carbendazim than their temperate counterparts. These findings appear to contradict those of Daam et al. (2009a), who did not find significant differences in sensitivity to carbendazim between invertebrate communities of the tropical regions of Thailand and temperate communities under semi-field conditions. Differences between the taxonomic composition of the species included in the temperate and Amazonian SSDs may be one of the reasons explaining the observed differences in sensitivity and were further investigated. Van Wijngaarden et al. (1998) conducted single-species laboratory bioassays with a number of eleven invertebrate species. They found that flatworms, oligochaets, amphipods and cladocerans were the most sensitive taxa, whereas gastropods and some insects were found to be relatively insensitive to carbendazim, and different ranges of sensitivity were observed among crustaceans. The toxicity dataset for temperate species used in the present study mainly relates to species belonging to the above-mentioned sensitive groups, while the Amazonian 
dataset included highly tolerant insects (even relative to the tolerant taxa identified by Daam et al. 2009a), one gastropod and one crustacean. Although the differences in taxonomic composition can introduce some bias in the sensitivity comparison, it cannot be concluded that this was the only cause of the difference in pesticide sensitivity, because the $\mathrm{LC}_{50}-96 \mathrm{~h}$ values calculated by Van Wijngaarden et al. (1998) for the less sensitive taxa are still considerably lower than the values calculated in the present study. So, it can be concluded, that Amazonian invertebrates seem to be less sensitive to carbendazim than their counterparts. Further studies should research whether these differences are due to the fact that the most insensitive species were tested and mainly originated from the black water habitat or that other factors can underpin the observed differences.

Implications for the use of temperate toxicity data for the risk assessment of pesticides in the Amazon and follow-up

The use of probabilistic methods like the SSD can be considered as useful tools in risk assessment of pesticides when trying to represent large assemblages of species with a rather limited number of toxicity data available, which is often the case for tropical regions like the Amazon. Several authors have studied the feasibility of SSDs for the derivation of safe environmental concentrations for aquatic ecosystems (Versteeg et al. 1999; Schroer et al. 2004; Maltby et al. 2005, 2009; Brock et al. 2006). For instance, Maltby et al. (2005) compared threshold concentrations derived from semi-field experiments with cut-off values derived from SSDs calculated from single-species acute toxicity for freshwater arthropods, demonstrating that median HC5 values result in a sufficient protection level for a single application of insecticides. The recent study by Maltby et al. (2009), which included not only insecticides but also herbicides and fungicides, showed that median HC5 values are not always protective against acute effects of fungicides on freshwater ecosystems (failing for three of the nine compounds studied), but the lower limit of the HC5 calculated for the most sensitive taxonomic group appeared to show a sufficient protection level for ecosystems treated with single and multiple pesticide applications. These findings have been verified for several organophosphate insecticides and for the fungicide carbendazim, and are presented in Brock et al. (2006) and Maltby et al. (2009).

Preliminary short-term WQC for freshwater ecosystems derived with Amazonian SSDs according to Maltby et al. 2005 and 2009 are shown in Table 5 for malathion, parathion-methyl and carbendazim, together with short-term WQC for the first-tier risk assessment of pesticides derived according to the European Uniform Principles for the registration of plant protection products in the market (EU 1997). The latter ones were calculated by dividing acute L(E)C50 values for temperate standard species of algae (green algae), fish (O. mykiss), and invertebrates (Daphnia magna) collected from the European FOOTPRINT pesticide database (www.herts.ac.uk/aeru/footprint/), by an assessment factor of 100 for animal species (i.e., fish and invertebrates) and 10 for algae. It was observed that the acute toxicity values for temperate standard test species of fish and invertebrates presented in Table 5 are lower than the toxicity data calculated for Amazonian fish and invertebrates (Tables 2, 3). Furthermore, temperate first-tier WQC show a conservative protection level when compared with the proposed Amazonian WQC derived from Amazonian SSDs. The results of this preliminary study suggest that the use of WQC derived with temperate standard test species and with larger assemblages of non-standard test species from the temperate region will result in a sufficient protection level for Amazonian indigenous species. However, these conclusions should be interpreted with caution since they are based on a rather limited number of toxicity data if we consider the whole range of fish and invertebrate species inhabiting Amazonian freshwater ecosystems.

The results of the sensitivity comparison between temperate and Amazonian species indicate that the inclusion of temperate toxicity data in SSDs, which can be used in higher-tier risk assessments to refine threshold concentrations derived solely with standard test species, will result in a sufficient protection level for Amazonian ecosystems,

Table 5 EC50 and LC50 values for temperate standard species, short-term water quality criteria (WQC) derived according to the European Uniform Principles, and short-term WQC calculated for Amazonian freshwater ecosystems $(\mu \mathrm{g} / \mathrm{l})$

\begin{tabular}{llllll}
\hline Pesticides & Algae EC50-72 h & Fish LC50-96 h & Invertebrates EC50-48 h & WQC Temperate & WQC Amazon \\
\hline Malathion & 13000 & 18.0 & 0.7 & 0.007 & $0.31^{\mathrm{a}}$ \\
Parathion-methyl & 3000 & 2700 & 7.3 & 0.073 & $0.09^{\mathrm{a}, \mathrm{b}}$ \\
Carbendazim & 8000 & 830 & 150 & 1.5 & $92.8^{\mathrm{c}}$ \\
\hline
\end{tabular}

\footnotetext{
${ }^{a}$ Median HC5 value for Amazonian arthropods

b Rico et al. (2010)

${ }^{c}$ Lower limit of the HC5 value for Amazonian invertebrates
} 
reducing the need of performing bioassays with a larger number of tropical indigenous species and pesticide combinations. However, one should keep in mind that the feasibility of using assessment factors applied to toxicity data of standard test species and the SSD approach to derive safe concentrations for freshwater ecosystems has been mainly validated with model ecosystem studies performed in temperate regions (e.g. Maltby et al. 2005; Van Wijngaarden et al. 2005; Van den Brink et al. 2006; Maltby et al. 2009). Only a few studies support the applicability of safe environmental concentrations derived from the firsttier risk assessment of pesticides with temperate standard test species in protecting tropical freshwater ecosystems (Daam et al. 2008, 2009a, b), and there are no studies available (non-) confirming the validity of the WQC derived with the SSD concept for tropical ecosystems. The applicability of threshold concentrations derived from SSDs for protecting tropical freshwater ecosystems still requires further investigation. The higher diversity of tropical ecosystems implies that the number of species potentially affected by pesticides should also be greater (Lacher and Goldstein 1997), and that, for example, the number of potentially affected species under the $5 \%$ cut-off value (HC5) of the sensitivity distribution should also be higher. Thus, when assuming the degree of contamination that is considered acceptable for temperate ecosystems (with 5\% of species affected) the structure of tropical ecosystems may be threatened, affecting a considerable number of species. On the other hand, the greater species richness of tropical ecosystems and the consequent complexity of the trophic relations can be considered an advantage over temperate ecosystems, as their functional redundancy is higher (Daam and Van den Brink 2010). The Functional Redundancy Principle has been considered suitable to evaluate the impact of pesticides on freshwater ecosystems adjacent to areas used for agricultural production (Brock et al. 2006). However, this protection goal may be questionable for Amazonian scenarios, where agricultural production is normally limited to small and isolated farms surrounded by watercourses considered hot-spots of species diversity, with a high degree of endemicity, and that are likely to be repeatedly exposed to pesticide contamination. The actual number of species that would be threatened and the redundancy of Amazonian freshwater ecosystems after pesticide exposure still require further indepth studies. Consequently, field or semi-field studies considering more realistic exposure regimes (i.e., multiple pulse exposure) should be performed with native species under typical Amazonian conditions (i.e., characterized by high temperatures, and slightly acidic waters with considerably low alkalinity and nutrient content) to investigate whether WQC derived from the lower-tier risk assessment approach and from SSDs, provide a sufficient long-term protection level for the structure and functionality of Amazonian freshwater ecosystems. These experiments will also elucidate (non-)differences in sensitivity to pesticide stress between Amazonian and other tropical (e.g. Thailand) and/or temperate (e.g. EU, USA) ecosystems by comparing threshold concentrations derived at a community-level in previous studies and will contribute to identify sensitive species that can be considered as surrogates for local freshwater ecosystems.

\section{Conclusion}

The effect of pesticides on Amazonian species assemblages has been already investigated for three different compounds (i.e., malathion, carbendazim and parathionmethyl). The inter-species comparison between Amazonian and temperate acute toxicity data derived from bioassays performed with freshwater fish and invertebrates showed that Amazonian organisms are no more, or less, sensitive to pesticide exposure than their temperate counterparts. Furthermore, Amazonian invertebrates were found to be significantly less sensitive to carbendazim than temperate invertebrates. Although the number of toxicity data representing Amazonian freshwater ecosystems is still very limited, the results of the present study support the initial use of temperate toxicity data for the risk assessment of pesticides for Amazonian freshwater ecosystems. Further studies should focus on assessing the feasibility on the use of WQC derived with temperate standard test species and SSDs on the protection of Amazonian freshwater ecosystems by performing model ecosystem studies.

Acknowledgments This study was funded by CAPES (Brazilian Ministry of Education agency) and Wageningen University and Research centre. The authors are indebted to Dr. Marcos V. B. Garcia from EMBRAPA (Brazilian Agricultural Research Corporation) for providing experimental facilities for the toxicity tests.

Open Access This article is distributed under the terms of the Creative Commons Attribution Noncommercial License which permits any noncommercial use, distribution, and reproduction in any medium, provided the original author(s) and source are credited.

\section{References}

Aldenberg T, Jaworska JS (2000) Uncertainty of the hazardous concentration and fraction affected for normal species sensitivity distributions. Ecotoxicol Environ Saf 46:1-18

Brock TCM, Arts GHP, Maltby L, Van den Brink PJ (2006) Aquatic risks of pesticides, ecological protection goals and common aims in EU legislation. Integr Environ Assess Manag 2:e20-e46

Castillo LE, De la Cruz E, Ruepert C (1997) Ecotoxicology and pesticides in tropical aquatic ecosystems of Central America. Environ Toxicol Chem 16:41-51

Cuppen JGM, Van den Brink PJ, Camps E, Uil F, Brock TCM (2000) Impact of the fungicide carbendazim in freshwater microcosms. 
I. Water quality, breakdown of particulate organic matter and responses of macroinvertebrates. Aquat Toxicol 48:233-250

Daam MA, Van den Brink PJ (2010) Implications of differences between temperate and tropical freshwater ecosystems for the ecological risk assessment of pesticides. Ecotoxicology 19:24-37

Daam MA, Crum SJH, Van den Brink PJ, Nogueira AJA (2008) Fate and effects of the insecticide chlorpyrifos in outdoor planktondominated microcosms in Thailand. Environ Toxicol Chem 27:2530-2538

Daam MA, Satapornvanit K, Van den Brink PJ, Nogueira AJA (2009a) Sensitivity of macroinvertebrates to carbendazim under semi-field conditions in Thailand: implications for the use of temperate toxicity data in a tropical risk assessment of fungicides. Chemosphere 74:1187-1194

Daam MA, Van den Brink PJ, Nogueira AJA (2009b) Comparison of fate and ecological effects of the herbicide linuron in freshwater model ecosystems between tropical and temperate regions. Ecotoxicol Environ Saf 72(2):424-433

De Zwart D (2002) Observed regularities in species sensitivity distributions for aquatic species. In: Posthuma L, Suter GWI, Traas TP (eds) Species sensitivity distributions in ecotoxicology. Lewis Publishers, Boca Raton, pp 133-154

Dyer SD, Belanger SE, Carr GJ (1997) An initial evaluation of the use of Euro/North American fish species for tropical effects assessments. Chemosphere 35:2767-2781

Ecobichon DJ (2001) Pesticide use in developing countries. Toxicology $160: 27-33$

EU (1997) Council Directive 97/57/EC of September 21, 1997; establishing Annex VI to Directive 91/414/EEC concerning the placing of plant protection products on the market. Off $\mathrm{J}$ Eur Communities L265:87-109

EU (2003) Technical Guidance Document on Risk Assessment in Support of Commission Directive 93/67/EEC on Risk Assessment to New Notified Substances and Commission Regulation (EC) No 1488/94 on Risk Assessment for existing Substances and Directive 98/8/EC of the European Parliament and the Council concerning the placing of biocidal products on the market. Luxembourg (LU): Office for Official Publications of the European communities. p 1009

Fittkau EJ (1982) Struktur, Funktion und Diversität zentralamazonischer Ökosysteme. Arch Hydrobiol 95:29-45

Furch K (1984) Water chemistry of the Amazon. The distribution of chemical elements among freshwaters. In: Sioli H (ed) The Amazon: limnology and landscape ecology of a mighty tropical river and its basin. Dr W. Junk Publishers, Dordrecht, pp 167-199

Howe GE, Marking LL, Bills TD, Rach JJ, Mayer FL Jr (1994) Effects of water temperature and $\mathrm{pH}$ on toxicity of terbufos, trichlorfon, 4-nitrophenol and 2, 4-dinitrophenol to the amphipod Gammarus pseudolimnaeus and rainbow trout (Oncorhynchus mykiss). Environ Toxicol Chem 13:51-66

Key PB, Fulton MH, Scott GI, Layman SL, Wirth EF (1998) Lethal and sublethal effects of malathion on three life stages of the grass shrimp, Palaemontes pugio. Aquat Toxicol 40(4):311-322

Kwok KWH, Leung KMY, Chu VKH, Lam PKS, Morritt D, Maltby L, Brock TCM, Van den Brink PJ, MStJ Warne, Crane M (2007) Comparison of tropical and temperate freshwater species sensitivities to chemicals: implications for deriving safe extrapolation factors. Integr Environ Assess Manag 3:49-67

Lacher TEJr, Goldstein MI (1997) Tropical ecotoxicology: status and needs. Environ Toxicol Chem 16:100-111

Laurance WF, Cochrane MA, Bergen S, Fearnside PM, Delamonica P, Barber C, D'Angelo S, Fernandes T (2001) The future of the Brazilian Amazon. Science 291:438-439

Lévêque C, Oberdorff T, Paugy D, Stiassny MLJ, Tedesco PA (2008) Global diversity of fish (Pisces) in freshwater. Hydrobiologia 595(1):545-567
Maltby L, Blake N, Brock TCM, Van den Brink PJ (2005) Insecticide species sensitivity distributions: the importance of test species selection and relevance to aquatic ecosystems. Environ Toxicol Chem 24:379-388

Maltby L, Brock TCM, Van den Brink PJ (2009) Fungicide risk assessment for aquatic ecosystems: importance of interspecific variation, toxic mode of action, and exposure regime. Environ Sci Technol 43(19):7556-7563

OECD (1992) Guidance document for aquatic effects assessment. Organization for Economic Cooperation and Development. Environment Monograph 92. Environment Directorate. Paris, France

Palawski DU, Knowles CO (1986) Toxicological studies of benomyl and carbendazim in rainbow trout, channel catfish and bluegills. Environ Toxicol Chem 5(12):1039-1046

Posthuma L, Suter GW, Traas TP (2002) Species-sensitivity distributions in ecotoxicology. Lewis, Boca Raton

Rico A, Geber-Corrêa R, Souto PC, Garcia MVB, Waichman AV, Van den Brink PJ (2010) Effect of parathion-methyl on Amazonian fish and freshwater invertebrates: a comparison of sensitivity with temperate data. Arch Environ Contam Toxicol 58:765-771

Römbke J, Waichman AV, Garcia MVB (2008) Risk assessment of pesticides for soils of the Central Amazon, Brazil: comparing outcomes with temperate and tropical data. Integr Environ Assess Manag 4(1):94-104

Saler S, Saglam N (2005) Acute toxicity of malathion on Daphnia magna Straus, 1820. J Biol Sci 5(3):297-299

Satapornvanit K, Baird DJ, Little DC (2009) Laboratory toxicity tests and post-exposure feeding inhibition using the giant freshwater prawn Macrobrachium rosenbergii. Chemosphere 74(9):1209-1215

Schroer AFW, Belgers D, Brock TCM, Matser AM, Maund SJ, Van den Brink PJ (2004) Comparison of laboratory single species and field population-level effects of the pyrethroid insecticide lambda-cyhalothrin on freshwater invertebrates. Arch Environ Contam Toxicol 46:324-335

SYSTAT (2007) SYSTAT software. Inc, Chicago

ToxRat: Toxicity Response Analysis and Testing (2003) ToxRat Solutions $\mathrm{GmbH}$, Aachen

Van den Brink PJ, Blake N, Brock TCM, Maltby L (2006) Predictive value of species sensitivity distributions for effects of herbicides in freshwater ecosystems. Hum Ecol Risk Assess 12:645-647

Van Vlaardingen PLA, Traas TP, Wintersen AM, Aldenberg T (2004) ETX 2.0. A program to calculate hazardous concentrations and fraction affected, based on normally distributed toxicity data. Bilthoven, the Netherlands: National Institute for Public Health and the Environment (RIVM). Report no. 601501028/2004. p 68

Van Wijngaarden RPA, Crum SJH, Ecraene KD, Hattink J, Van Kammen A (1998) Toxicity of derosal (active ingredient carbendazim) to aquatic invertebrates. Chemosphere 37:673-683

Van Wijngaarden RPA, Brock TCM, Van den Brink PJ (2005) Threshold levels for effects of insecticides in freshwater ecosystems: a review. Ecotoxicology 14:355-380

Versteeg DJ, Belanger SE, Carr GJ (1999) Understanding singlespecies and model ecosystem sensitivity: data-based comparison. Environ Toxicol Chem 6:1329-1346

Waichman AV, Römbke J, Ribeiro MOA, Nina NCS (2002) Use and fate of pesticides in the Amazon state, Brazil: risk to human health and the environment. Environ Sci Pollut Res 9:423-428

Waichman AV, Eve E, Nina NCS (2007) Do farmers understand the information displayed on pesticide product labels? A key question to reduce pesticides exposure and risk of poisoning in the Brazilian Amazon. Crop Prot 26:576-583

WHO (1993) Environmental health criteria No 149. Carbendazim. International programme on chemical safety. ISBN 924 1571497 